\title{
Nature matrix: reconnecting people and nature
}

\author{
Robert Michael Pyle
}

\begin{abstract}
Many individuals and societies are no longer connected to the more-than-human world in such a way as to ensure a sustainable future. As such connection has diminished, environmental challenges have multiplied and influences for estrangement intensified. I review the importance of direct, intimate encounter with places and organisms on the attitudes of the young, as well as the significance of biophilia. The result of the loss of contact and subsequent alienation is the Extinction of Experience: an inexorable cycle of disconnection, apathy, and progressive depletion. I describe an effort to demonstrate this effect. Small, humble habitats, especially in urban settings, can be as important as big reserves in awakening biophilia. Biophobia, abetted by the loss of such habitats, the rise of the virtual in place of actual experience, economic inequalities, and overpopulation, further feeds the downward spiral of extinction and disaffection. The climate of global corporate growth that
\end{abstract}

now prevails is inimical to sustainability, as is the current state of ecological illiteracy. Radical change is therefore necessary to address both economic disparity, in the direction of minimal ownership rather than maximum consumerism, and educational reform that places nature at the centre rather than the margin of the curriculum. I present a six-point programme, called Nature Matrix, for an alternative social and ethical paradigm. Rather than a pragmatic plan for the near future, Nature Matrix is a model for essential, incremental change, a dream whose eventual adoption may enhance chances for reconnection and for ecological survival itself: at present, a deeply uncertain prospect.

Keywords Biophilia, ecological literacy, environmental connection, extinction of experience, globalism, land ethic, nature study, sustainability.

\section{Introduction}

At the outset of the 21st century there is no longer any doubt that a strong individual sense of connection to nature and natural processes is utterly essential to the healthy coexistence of humans with their biological neighbours and physical setting. We also understand that as such a sense has paled, withered, and is finally failing, so is our ecological condition collapsing and our future contracting. As Steven Sanderson of the Wildlife Conservation Society has put it: "Wild nature is in deep distress, and whatever their occasional protestations, the international institutions charged with Earth's care are not managing it with an eye on 'sustainability.'" Sanderson (2002) also identifies a condition that I consider to lie at the very foundation of the ecological crisis, alongside overpopulation and economic disparity: "In the foreseeable future, most of the world's population will not know nature in any direct way."

All aboriginal cultures were peopled by excellent naturalists, or else they perished, both as peoples and as individuals. Feudal oppression was made more tolerable

Robert Michael Pyle 369 Loop Road, Gray's River, WA 98621, USA. E-mail: tlpyle@willapabay.org

Received 13 December 2002. Revision requested 12 February 2003. Accepted 26 March 2003. by people's knowledge of the countryside and its supportive systems, enabling bare survival under privation. When the majority of the population of most regions was agriculturally based, and settlements largely rural, most people still connected with the physical world on a daily basis. Even deep into the industrial era, the American Nature Study movement (Pyle, 2001), and parallel educational practices in the UK and elsewhere, sought to promote essential familiarity of common people with local flora and fauna. But after World War II, flight from the countryside to the city, combined with overpopulation and mercantile expansion, frayed the remaining relationship. Today, as the virtual finds its apotheosis at the expense of the real, the separation has progressed to a point where reattachment may be impossible, and long-term survival of human culture is not at all a foregone conclusion.

The assumption that responsible behaviour towards the environment is closely related to people's feelings of personal connection to nature finds support in nearly every conservation history or bio-philosophical treatise (Leopold, 1949; Bates, 1950; Hay, 1987; Scheffer, 1991). It finds its fundament in the biophilia hypothesis (Wilson, 1984; Kellert \& Wilson, 1993), which posits the existence of an innate affection for living things, developed to a greater or lesser extent in all human beings. Biophilia works, according to Wilson, because "To the extent that 
each person can feel like a naturalist, the old excitement of the untrammelled world will be regained", and because this "formula for re-enchantment" can lead to conscientious behaviour. Many related authors (Carson, 1965; Cobb, 1977; Pyle, 1993; Sobel, 1993; Nabhan \& Trimble, 1994; Orr, 1994; Kellert, 1997; Kahn, 1999; Thomashow, 2001; Flicker, 2002) argue for childhood bonding with natural places and organisms as the essential key to arousing biophilia and concomitant caring behaviour. The principle is so well established as to be considered canon in many quarters, although in practice it is increasingly observed mainly in the breach.

To an alien observer, it may seem that humans pay great obeisance to their ties with other species today. After all, the majority of cultures are still dependent upon daily contact with their physical and biological surroundings for their food and shelter. In fact, many of the rural poor in developing countries still rely on a close knowledge of nature. Even Western industrial society attends conspicuously to 'nature' in the context of outdoor recreation. Natural history and environmental writing has never been healthier in terms of books published and programmes in universities and field institutes. Sales of field guides remain robust, and titles proliferate annually. Membership rises in bird, butterfly, and native plant societies at a respectable rate, while birding and butterflying make larger and larger contributions to ecotourism around the world. Vast numbers of people participate in gardening, angling, hunting and other outdoor pursuits. Nature television commands respectable market shares, and parks and visitor centres attract hordes of holidaymakers, day trippers, and schoolchildren in search of fresh air and information as well as recreation. Conservation societies thrive, and the incipient green theology movement brings spiritual concerns and energies to bear upon the more-than-human world of 'the Creation'. If all this is true, how can the contention be made that people need to reconnect with nature?

For one thing, the above refers chiefly to the temperate, industrialized world, where leisure time activities are supported by disproportionate resource consumption. Arguably the societies most distantly removed from direct daily dependence on lands and waters are also those where conspicuous nature recreation emerges, and where the vast preponderance of world resources are consumed. From North America, and other aspirants towards its standard of living such as Japan, comes most of the relentless pressure on the biosphere for ecological services, biomass and genetic information.

In contrast, the great majority of humanity occupies developing countries in tropical and subtropical climes where poverty often prevails and few can afford to abstract their relationship with nature into avocation or recreation. While some such cultures still live in relatively close concert with their surrounding ecological communities, more and more peoples find their traditional relationships forced into unsustainable patterns through overpopulation, hardship, externally based resource mining, and financial and agricultural colonialism taking advantage of an imposed cash economy. For example, as a biologist in Papua New Guinea, I observed many examples of the breakdown of traditional patterns of 'bush' resource use and husbandry under the malign influence of oil palm plantations, logging, and other introduced forms of cash generation, extraction, and dependence. Social disintegration inexorably follows.

For another thing, I see a discrepancy between apparent connection and real depth of contact. Listing birds and cultivating roses, while benign and admirable activities, do not necessarily equate with profound association. In many parts of the world, notably the most developed, contemporary society lacks a widespread sense of intimacy with the living world (Pyle, 1993). Naturebased recreation commonly results in superficial contact, as demonstrated in the extreme by the competitive sport known in Britain as bird 'twitching', whereby the organism itself becomes a mere game-piece for a tally score. The landscape parallel presents a family in a motorhome ticking off the Grand Canyon before emptying the holding tank and motoring on towards Zion. Many tourists, members of natural history groups, and participants in countryside pursuits merely skim the surface of the landscape, reaping a shallow reward and a weak relationship; there is a continuum, of course, from casual to devoted. Yet the great majority of the people associate with nature even less. At least the skimmers are aware of nature around them. As for the others, whose lives hold little place for nature, how can they even care? People who care, may make choices to conserve; but people who don't know, don't even care. What is the extinction of a condor or an albatross to a child who has never known a wren?

Shallow contact with nature leads to shallow solutions for conservation. During a recent hotel stay, I picked up a card on the pillow asking patrons to consider reusing their linens in order to save water and detergent. This is doubtless a positive development in the hotel industry. However, the card was grandiosely titled "SAVE MOTHER EARTH!" If people feel that they are discharging their responsibility as conservationists by sleeping twice on their sheets in a premium hotel, the overall effect could be counterproductive. Likewise the level of interpretation in most visitor centres, the depth of detail in environmental education, and the penetration of media representations of nature often approach the shallowness achieved by the casual birdticker. This is not always the case, and examples exist of admirable depth achieved in these fields, but those 
do not reach many people. Not that full immersion guarantees epiphany either: people who spend $\$ 8,000$ to travel to Antarctica and view emperor penguins up close may forge a deep personal connection thereby, examine their lives, and act accordingly; or they may remain blind to the impacts and implications of their elite choices in the seductive glow of the southern summer. Intimacy with nature is only a starting point.

On the opposite side, obvious examples of our estrangement from nature abound: the mass toleration of expansive, even ubiquitous pesticide usage, including widespread home and neighbourhood toxins commonly believed to be far safer than they arguably are; the proliferation of large, heavily fuel-consumptive SUVs (sports utility vehicles), huge personal diesel and gasoline pickup and four-wheel drive trucks; general acceptance of off-road vehicles, personal water craft, leaf-blowers, and other two-stroke engine devices that severely pollute the air and the 'sound-shed'; indifference towards habitat loss in and around human settlements; societal consent for laws governing mining, grazing, forestry, industry, waste disposal, and transportation amounting to licence to pollute and destroy; and an overall embrace of affluence, consumption, waste, and sheer human expansion to a degree that cannot conceivably be sustainable in any form we would want to live with.

Furthermore, many individuals suffer from a deepset antagonism towards nature that cannot be helpful to conservation. Of course our relationship with other species is inevitably double-edged. As McNeely (2002) points out, we sometimes find ourselves in the position of trying to conserve animals in one place that kill or conflict with people elsewhere, or even in the same places, such as elephants or tigers. Many other species, especially certain herbivorous insects and exotic invasive species, are important competitors with humans for food and fibre, and others serve as vectors of disease. Agricultural response may prove necessary, but can cause enormous by-kill of non-target species (Pyle et al., 1981). Mass spraying may also have toxicological consequences for public health greater than the potential epidemiological danger from the targets, as I believe is likely to occur with the current West Nile Virus scare and the chemical reaction to it. Just as dangerous, our fixation on a relatively small number of pests and enemies leads to a general hatred of insects: clearly a maladaptive attitude in a world where most of life is insect life. Surely, if meaningful connection is to be forged, we should seek to avoid such polar abstractions. Even as we seek ways to protect essential resources from competitors, our schools should inculcate widespread public equanimity towards all nature (Pyle, 1986). This is the only stance that long-range human adaptability will tolerate.
The loss of everyday intimacy and tolerance both stem partly from the rapid decline of children's contact with their special places. As mentioned above, Sobel (1993) and others have shown repeatedly how important their wild nooks have traditionally been for children in their growing up and connecting with nature. Richard Mabey (1973) coined the term "unofficial countryside" to refer to the secondary habitats, often abandoned industrial sites or marginal urban waste ground, where we can make contact with plants and animals when officially protected natural areas are not to hand.

In fact, the 'official countryside' of parks and reserves often fails to deliver intimate contact to the curious young because of fences, mandatory paths, no-net rules, and other restrictions. Botanic gardens and zoos can play a role in rebuilding the bridges between people and other species, to be sure, as they always have. However, such artificial assemblages of largely exotic species share some of the same liabilities as reserves and protected areas when it comes to romancing intimacy. They are useful for gaining first-hand acquaintance with an array of organisms from various, distant habitats. But without the context of the local, they may not mean much more than Disney World. It is the opportunity for the young to explore, dig, prowl, play, catch, and ultimately discover, among indigenous local plants and animals, that truly forges connection. In this sense, a vacant lot may be more valuable than a nature reserve or an arboretum.

Such humble, hand-me-down habitats have traditionally played an enormous role in acquainting the young, in particular, with the more-than-human. When urban and suburban in-filling and edge sprawl displace the vacant lots and other open ground, children lose the opportunity to make meaningful contact close to home. Such losses conspire with the seductive tug of computer games, the internet, over-scheduling, and parents' fear of real or imagined dangers to limit children's freeranging outdoor time. I fear that all these influences will lead to a generation of youths with no personal bond with a particular place they can call their own, and this in turn will begin to breed a populace that cares less and less about its physical surroundings (Pyle, 2002). I believe that the innate drive towards biophilia is a reality, along with the impulse of the young to reach in that direction. Recently, in a shopping mall, I witnessed a group of boys skipping stones over a pond, just as any bunch of lads in the country may do. Only the 'stones' were quarter-dollars, and the 'pond' was an artificial, geometric water feature in the mall. The boys told me they had no outdoor place to skip stones, nor any experience at it, yet they had spontaneously recovered the quarters from the fountain, not to keep and spend, but to skip over the water's 
surface. What might it have meant for these boys if their encounter had also featured frogs, reeds, dragonflies, and the smell of wet mud?

The decline of individual and corporate connection with the world itself leads to a cycle of loss and disaffection that I have called the Extinction of Experience (Pyle, 1978, 1993). Essentially, the extinction of experience syndrome works as follows: when common species of plants and animals (as well as cultural, architectural, or any other features of diversity) become extirpated in one's everyday environs - within, that is, one's radius of reach - one grows increasingly inured to their absence. (The radius of reach is smaller for the poor, the very old, the very young, and the disabled.) That is, as the richness of the neighbourhood diminishes, the power of the neighbourhood to fascinate, arouse, excite, and stimulate also passes into dullness, ennui, and apathy. Those who know and recognize less, care less, and therefore act less, leading to still more losses. The sequelae of extinction and alienation are further loss and greater detachment, round and round. So the extinction of experience precipitates a cycle of disaffection, degradation, and ultimate separation from nature.

It is also important to note that an element of the actual wild is vitally important in heading off the extinction of experience. This follows from Wilson's observation (1984) that "People can grow up with the outward appearance of normality in an environment largely stripped of plants and animals ... yet something vitally important would be missing, not merely the knowledge and pleasure that can be imagined and might have been, but a wide array of experiences that the human brain is peculiarly equipped to receive.... On earth, no less than in space, lawn grass, potted plants, caged parakeets, puppies, and rubber snakes are not enough." We must also now add, neither are virtual images. The shimmering pixels on a computer screen can never substitute for the shimmering scales on a butterfly's wing. Direct, personal contact with other living things affects us in vital ways that vicarious experience can never replace.

Particularly because the common modern condition is more biophobic than biophilic, as illustrated by robust urban sales of household biocides, benighted rural attitudes towards predators, and many other behaviours, the way towards an enlightened state vis-á-vis other species is steeply uphill and crooked. Yet if the mechanisms of the growing disconnect are clear, how may the consequences be demonstrated? Empirically, since one-on-one contact between the human mind and extrahuman life is the ticket to awaken biophilia, and assuming Wilson is right that the awareness and refinement of this condition can lead to behavioural modification in favour of conservation, then the larger implications of a depauperate outdoor setting should be clear. Wilson further states that "to explore and affiliate with life is a deep and complicated process in mental development," and that "to an extent still undervalued in philosophy and religion, our existence depends on this propensity, our spirit is woven from it, hope rises on its currents." It follows that hope, spirit, and existence all suffer when the affiliation is forfeit. So another definition of the extinction of experience may be the failure of biophilia. "Is the exploration of the natural world just a pleasant way to pass the golden hours of childhood," asked Rachel Carson (1965), "or is there something deeper?" We can agree that, indeed, there is something deeper. Plumbing its depth is another matter.

I have attempted to quantify the extinction of experience (Pyle, 2002), by employing the rates of urban extinctions of butterflies to calculate the quantity $\Delta \mathrm{N}$ as a measure of the degree of natural change and as an indicator of lost opportunity for contact (where $\Delta \mathrm{N}=$ $\%$ extinction/Area/Time* 1,000). Comparing figures for butterfly extinctions over time and area in four American cities (Staten Island, New York; San Francisco and Los Angeles, California; Aurora, Colorado) the study found that the dramatically developing edges of Denver, Colorado, in the town of Aurora, produced a value for $\Delta \mathrm{N}$ four orders higher than that of the larger but more mature cities. The data showed that the opportunity for experiencing nature in the cities studied has diminished measurably, most of all in the most rapidly suburbanizing of them. Factoring in the high proportion of biologists, conservationists, and other resource professionals who gained their initial inspiration through contact with insects, $\Delta \mathrm{N}$ as indicated by urban butterfly extinction may be considered a reliable index of the extinction of experience in action and a predictor of its effects. While it is not possible to demonstrate that environmental leaders will no longer arise from the streets of a place with a high $\Delta \mathrm{N}$, such as Aurora, it seems reasonable to conclude that the likelihood of youngsters becoming avid naturalists and conservation voters has been reduced in parallel with their home town's butterflies and the diversity they represent. To further test the point, $\Delta \mathrm{N}$ could be compared against changing attitudes towards nature. Although the latter is difficult to quantify, methods for doing so have been developed by Stephen Kellert of Yale University (Kellert, 1985). While the principle of the extinction of experience has been widely adopted and quoted, such further studies represent a promising new avenue of investigation that may point towards practical countermeasures.

Reconnecting with nature is not a matter of reversing the fall, getting back to Eden, or approximating the peaceable kingdom. These states never occurred. The 
fact is that people have always been at odds and in competition with the wild in many ways. But we have also co-evolved with every other species with which we have been in long-time contact, and for most of our evolutionary history, the struggle and cooperation commonly involved the death of individuals but no real threat to the species or its supportive matrix. The balance that aboriginal peoples are routinely said to have existed in, vis-á-vis nature, owes largely to a pre-industrial state, low population, and generally low impact living. The respect that such cultures are commonly assumed to have exhibited (for example, American Indians) may be real or romanticized. But when technology advanced, as with Clovis points, so did human impact, perhaps to the extent of Pleistocene overkill of large North American mammals. Nonetheless, Lopez (2001) considers the "way of being" of native peoples to be fundamentally different from the way modern naturalists are tied to nature. He believes that ever since Gilbert White, naturalists have been "searching for a way back in to nature" while native peoples "have been at pains not to leave." Whether or not this applies generally in complex indigenous settings, the principle and the metaphor stand: our challenge now is to find that way in, while reducing the cumulative impacts of the industrial revolution and population increase facilitated by industry and agriculture.

Dedicated people have taken up that challenge in unjaded earnest and to good effect. Much of this work falls in the realm of restoration. To take just one example among any number of notable retrofittings of habitat for people and other species, consider the Limberlost. This extensive swampland in northeastern Indiana gained international fame through the enormously popular novels of Gene Stratton Porter in the early twentieth century, such as A Girl of the Limberlost. Yet, by 1916, most of the Limberlost had been drained and converted to arable fields. After the better part of a century of elegiac existence in the novels alone, the Limberlost is now being reassembled, reflooded, and reforested with native species by Limberlost Swamp Remembered, a group begun by one local farmer (Brunswick, 1999). Even lost life forms may have a future, such as the spectacular reintroduction of the large blue butterfly Maculinea arion into England from Sweden, after extinction of the British subspecies and recovery of its habitat through applied ecology spearheaded by Jeremy Thomas (New et al., 1995). In an American counterpart, I have suggested the experimental reconstitution of the extinct Xerces blue Glaucopsyche xerces from the nearest surviving genotypes, now that its habitat in San Francisco is being restored (Pyle, 2000).

But such resurrection ecology will never reverse the majority of human-mediated extinctions, nor will community-based restoration efforts reverse disastrous global trends that will ultimately undo all of our best efforts without adequate address. Likewise, no matter how many people take up natural history or outdoor pursuits, nature conservation will not advance without massive collective will for large-scale change. Gardening and birding won't do it, if basic behaviour remains the same. When I see butterfly watchers driving SUVs, I question their fundamental understanding and devotion to the necessary revolution in consumption. Birders who vote for non-conservation candidates do not vote for birds. The current high popularity ratings for George W. Bush among the American public do not square with other polls that show most Americans are deeply concerned about the environment, for he and his cabinet choices comprise the worst conservation administration since Ronald Reagan's.

The plain fact is, world culture will never become connected to nature in a way that will ensure survival in the military/mercantile climate that now prevails. Exxon Corporation took a typical stance towards the aftermath of the Exxon Valdez oil spill, whose casualties were sea otters, seabirds, marine life, salmon, and human fishing communities: business first. The November 2002 oil spill off the coast of Spain may have equivalent impacts, and an equivalent attitude may be expected. The New York Times News Service (Murphy, 2002) recently reported that "The Bush administration has approved construction of a geothermal power plant in the Modoc National Forest, a remote volcanic field near California's border with Oregon that local tribes consider sacred," reversing a Clinton administration decision. A Native American spokesman meeting with the director of the Bureau of Land Management and the chief of the Forest Service reported that they expressed sympathy for the Indians' plight. "They said they recognize our culture," said Gene Preston, chairman of the Pit River Tribes, "but also the culture of capitalism." As long as the culture of capitalism trumps the commonweal, natural and cultural diversity will deteriorate. "Humankind" as an entity, let alone the rest of nature, has no legal standing, shareholder votes, or seats on corporate boards. Therefore, the only reconnection that will be truly significant must also be radical.

Every national economy, and the global economy of the North American Free Trade Agreement, the General Agreement on Tariffs and Trade, the World Trade Organization, and the European Economic Community, assumes growth to be the only acceptable state of affairs. But a permanent state of growth means continued carbon release, ozone depletion, human population expansion, aquifer depletion, toxic contamination, resource depletion, species extinction, class partition, warfare, disease and, ultimately, breakdown. A cliché 
among business people is "if you're not growing, you're dead." But in ecological, epidemiological, and oncological terms, beyond a certain point, if you're still growing, you're going to be dead. The radical, steady-state precepts of Zero Population Growth (Population Connection, 2003), the E. F. Schumacher Society (E. F. Schumacher Society, 2003), and other movements that challenge the grow-until-you-bust paradigm are not much in fashion today. One who argues this position, Murray Bookchin (1989), considers our addiction to growth evidence that we live in "an inherently anti-ecological society." The mercantile, deeply philistine ethic that drives the global business and political culture cannot help but subordinate the so-called natural world to the immediate commercial opportunities of the one species that insists upon an epistemology that places it in some other world by itself. Because all others aspire to follow where the USA leads, the most frightening prospect for the biosphere is that China, India, and other populous regions may succeed: all those cars, plastics, silicon chips, pesticides and second homes, speeding the metastasis along.

So the kind of radicalization I believe is required has two chambers to its heart. Firstly, a new, responsible economy that addresses economic disparity without feeding the drive towards perpetual growth and acquisition. There is no question that the alleviation of poverty must precede, or at least parallel, conservation. But it mustn't be a matter of the have-nots matching the haves, which would simply lead to a quicker collapse. Rather, both must approach a sustainable mean that will be much more than most enjoy now but very much less than some command. As the pre-eminent Korean poet and social thinker Ko Un said recently, addressing the Association for the Study of Literature and Environment-Japan in Okinawa, there will be no peace for people or for the rest of nature until an ethic of minimal ownership prevails. But the current state, enunciated by poet Gary Snyder at the same conference, is exactly the opposite: "the elevation of greed and gain to an iconic prominence." Not everyone agrees that a viable conservation future is incompatible with corporate capitalism. Sanderson (2002) believes that greater private investment in conservation, codes of conduct to shift "the behavioural canons of economic growth and development," and novel pragmatic alliances between NGOs and the corporate sector may give nature, and us, a chance at a decent future. But this presumes such qualities as a corporate conscience, restraint, and an awareness of limits. While an enlightened 'natural capital' approach may work on a modest and local scale, global corporatism shows no signs of possessing or living by such traits.

Secondly, an all-out campaign to reduce ecological illiteracy, which is epidemic and is another form of debilitating poverty. For the fact is, the majority of people are connected with nature in their lives, whether they know it or not: they necessarily consume that which comes from nature, and their recreation, avocation, or work often binds them closer. But they are also deeply, profoundly ignorant of the working parts of the world around them, and thus prevented from having any sort of close relationship with extra-human nature. Whereas it was once considered a good thing for people to be at least roughly acquainted with their local flora and fauna, this pretence has long since dropped away. The number of people who have even a rudimentary knowledge of their non-human neighbours, just their names, let alone their ways of life, is vanishingly small. This is truly the crux of the crisis, as I see it. Because if the people were closely acquainted with the plants and animals they live among and depend upon, the eco-crimes they permit and abet and conduct and sponsor daily would not be so easy to bear, let alone countenance. Conversely, the development of a political and economic system that depends upon infinite growth could only have arisen in a state of grievous loss of common knowledge. That loss was the true Fall.

So how far have we fallen? To be sure, extraordinary changes in conservation ethics have occurred over the last 100 years. The plumes of wild birds are no longer used in millinery, and more animals are hunted with cameras than high-powered rifles. However, diminishing protection of wetlands and the growing 'bushmeat' trade offset such gains. While eloquent voices (such as E. O. Wilson's) have spoken out for the primacy of understanding the dimensions of biological diversity while there is still time, survey and classification efforts have only been weakening, and major regional centres closing down. The recent budget-cutting elisions of the renowned entomology department of Oregon State University and closure of the Nebraska State insect collection are merely recent American examples, mirrored widely. At a time when the need for knowledge has never been greater, the tools for knowing are withering; and it has become a cliché that many species will become extinct without ever having been described. This, at a time of unmatched affluence in the developed world! But in one sense, this outcome is not surprising. Aldo Leopold in A Sand County Almanac (1949) wrote that "Land-use ethics are still governed wholly by economic self-interest, just as social ethics were a century ago." Half a century forward, that fact has not fundamentally changed. As Barry Lopez (2001) summed the situation, "Recognize that a politics with no biology, or a politics without field biology, or a political platform in which human biological requirements form but one plank, is a vision of the Gates of Hell."

Yet we're still falling, both in the developed and developing worlds. Most demographers predict that the 
world population of humans will level off at 8-9 billion near the year 2050. Can we wait to establish a new and closer relationship with what's left then? I don't think so, because not much will be left, and societal suppleness will be much reduced in all regimes, should we survive to see such utterly unsustainable numbers.

I am not sanguine that a better path is still possible. If it were, however, it would have to recognize something else enunciated by Leopold: "The 'key-log' which must be moved to release the evolutionary process for an ethic is simply this: quit thinking about decent land-use as solely an economic problem. Examine each question in terms of what is ethically and aesthetically right, as well as what is economically expedient." In the end, for any paradigm shift to succeed in time, it must embrace the central tenet of Leopold's Land Ethic: "A thing is right when it tends to preserve the integrity, stability, and beauty of the biotic community. It is wrong when it tends otherwise."

This brings us finally to a vision for a new and wholly different ethical regime. I call this dream Nature Matrix, a term that recognizes the only acceptable long-term way for us to view the rest of the natural world: as completely, irreducibly bonded into a functioning body that we cannot escape. I use the term "matrix" in the biological sense, meaning the intercellular substance that binds all the rest, similar to how Wilson (1984) employs it when he says that "other organisms ... are the matrix in which the human mind originated and is permanently rooted." Nature Matrix has six essential elements:

1) Land Ethic Basis. Every decision is subject to the essential test of the Leopoldian doctrine: "A thing is right when it tends to preserve the integrity, stability, and beauty of the biotic community. It is wrong when it tends otherwise." There is, of course, room for interpretation here; but reasonable persons in possession of real knowledge about "the biotic community" (see (2) below) will eventually come to judge most cases alike. Even so, enigmatic instances would arise such as eucalypts in California, harmful invasive exotics overall, but essential for overwintering monarch butterflies that have adapted to their groves in the absence of the original coastal forest structure. Panels of ecologically sophisticated citizens will explore and settle such disputes on a place-by-place basis.

2) Nature Study. "Nothing makes sense except in the light of the local floras and faunas," according to E. O. Wilson, and Korean poet Ko Un says "nature hates modern education the most." Education will be based on natural history, with all other topics taught in relation to it. Far from the exception it is today, "environmental education" forms the core of the new pedagogy, both at home and in the schools. Basic educational goals include not only literacy and numeracy, but also essential acquaintance with the ecosystem of home. Children come to know many of their local plants and animals on a first-name basis as a matter of course. Higher education once again emphasizes and honours the survey and cataloguing of natural diversity, as well as the extended study of their lives and interrelationships once they have been classified. Nature Matrix places human culture and history in their relative importance to the larger world. The arts are held in equal regard and are practised in cooperative synchrony with the sciences.

3) Local Focus. As Leopold recognized, the main split in conservation is between local and federal or state control. As a resident of a rural, resource-dependent county, I can affirm this fact today. Country people devoutly believe that local control is the best, and only acceptable, kind, and that left to their own devices, local folks will do the right thing. In practice, this seldom happens, subverted as it is by economic self-interest, myopia, lack of power, and absence of ecological knowledge. Thus governmental regulation has necessarily imposed limitations for the larger good, as in game laws. But such restraints are temporary, due to regime change. Lacking place-specific knowledge, regulators are often unequipped to render decisions tailored to local biological or social conditions. In Nature Matrix, the essential units of decision-making are locally informed but centrally monitored according to (1) above.

4) Consensus Rule. One reason conditions remained stable in many Papua New Guinean villages far into modern times is that decisions were made by consensus, not by majority rule. It takes forever to reach consensus, so not much damage is done in the meantime. Not until democracy and a cash economy were imposed in the 20th century did this pattern erode, a pattern that also tended towards sustainability in a state of high natural diversity. Of course, totalitarian corporatism leads to the same ecological pass. Nature Matrix replaces both capital-controlled democracy and autocracy with a biocratic form of rule by mutual consent. Change, progress, and innovation will be slow and highly conservative in a sense almost opposite to its common political connotation today.

5) Communitarian Justice. Human rights are understood as underlying Nature Matrix, and extended to the broader community of life. These do not include the right to accumulate wealth and material goods or profits in violation of the Leopoldian doctrine, nor the right to reproduce without limit. Economic development seeks a standard of minimum rather than maximum ownership, and an ideal of enough, rather than having it all. Equitable distribution of wealth and population control are achieved through individual responsibility, restraint, and personal empowerment growing out of 
(2) above, rather than by coercion. Private property rights are subordinated to the good of the whole, and a sense of community well-being is cultivated in place of the familiar drive for individual acquisition. Freedom recognizes and implies responsibility as well as autonomy. Religious choice is free, with spiritual energies encouraged to regard the care of the here and now, rather than relying on some hypothetical hereafter.

6) Ecological Restoration. Fixing damaged ecosystems and communities forms the basis for the human enterprise, beyond the sustainable production and conservation of essential materials. Remaining wilderness and old growth forests all remain that way, agriculture being confined to existing cropland. Damaged lands and waters will be cleaned, replanted, and rewilded. Reuse, recycling, and durability of goods replace an ethic of obsolescence, replacement and waste. The air, water, quiet, and night sky are all sacrosanct, with the burden of proof on potential polluters to show that their activities are harmless. The manufacture and use of synthetic chemicals become the rare exception rather than the rule. Farming is organic, small to modest in scale, and polycultural, in league with soils and organisms. Consumption emphasizes the local. Warfare and its weapons ultimately become irrelevant as the common struggle is realized and joined.

If Nature Matrix sounds utopian, it is actually a fairy tale. Lacking any corrective to greed and power, it equals the vaunted Earth Charter (Earth Charter, 2003) in its fond naiveté. I have no idea what sort of authority could possibly bring it about. A benevolent empire that saw the light and decided to impose these conditions could presumably do so only through violent coercion, which is inimical to the whole concept. However, if such a vision were to be progressively adopted and promulgated as a blueprint by organizations and various levels of authority, I can imagine that slow movement in this direction may be possible.

Nature Matrix could also arise in adaptive response to the aftermath of some level of ecological and civil collapse. If all of the important community and conservation struggles underway now and in the future would begin to think more and more about reconnection on a truly Leopoldian level, they may lay the dispersed groundwork for a kind of recovery based on a new way of thinking. Like monasteries in the Dark Ages, they could preserve the methods, the knowledge, the honourable impulses. Then if a critical mass of humanity survived, along with enough of the earth to be worth living for, something like Nature Matrix could conceivably evolve out of the rubble. If this seems like cold comfort in perilous times, it may nonetheless be something to hope for. Either way, reconnecting people with nature - at least, reconnection worth the name - will best be accomplished after the old, corrupted relationship finds a whole new face.

Of course, I would prefer to believe that we may succeed through less drastic measures than environmental Armageddon. If conservationists stay the course, perhaps we can. But time is short. As Gus Speth, Dean of the Yale School of Forestry and Environmental Studies, recently wrote: "A great tragedy is fast unfolding. More than 20 years ago, the alarm was sounded regarding threats to the global environment, but the environmental deterioration that stirred the international community then continues essentially unabated today. The steps that governments have taken over these past two decades include the negotiations of numerous international agreements and represent the first attempt at global environmental governance. It is an experiment that has failed" (Speth, 2002). In echo comes "A planetary defeat: the failure of global environmental reform," J. B. Foster's informed assessment of the current state of ecological affairs (Foster, 2003). "The first Earth Summit in Rio de Janeiro, Brazil in 1992 generated hopes that the world would at long last address its global ecological problems and introduce a process of sustainable development," wrote Foster. "Now, with a second summit being held 10 years later in Johannesburg, that dream has to a large extent faded."

Nature Matrix imagines a fundamentally different dream, with a new kind of environmental governance, one whereby humanity accedes its ambitions to natural limits. A place where, as John Hay wrote in 1969, there may still be "a chance to live and let live, a chance ... to get rid of that terrible, isolating concept of man as the lord of creation." But Hay had it just right when he said, "We have a great deal of exploring to do in order to find the place where we share our lives with other lives, where we breathe and reproduce, employ our sight, and join the breadth of chances not as separate, unique entities with doomsday on our docket but as vessels for universal experience."

Ultimately, reconnecting people with nature is a nonsense phrase, for people and nature are not different things, and cannot be taken apart. The problem is, we haven't yet figured that out.

\section{References}

Bates, M. (1950) The Nature of Natural History: A Study in the Approach of Science to the Living World of Which we Form a Part. Charles Scribner's Sons, New York, USA.

Bookchin, Murray (1989) Death of a small planet: it's growth that's killing us. Progressive, 53, 21.

Brunswick, K. (1999) 20,000 Years of Limberlost Swamp. Limberlost Today, Bryant, USA.

Carson, R. (1965) The Sense of Wonder. Harper and Row, New York, USA. 
Cobb, E. (1977) The Ecology of Imagination in Childhood. Columbia University Press, New York, USA.

Earth Charter (2003) The Earth Charter Initiative. http:/ / www.earthcharter.org [accessed 28 March 2003].

E.F. Schumacher Society (2003). The E.F. Schumacher Society. http:/ / www.schumachersociety.org [accessed 28 March 2003].

Flicker, J. (2002) Audubon, the Second Century: Connecting People with Nature. National Audubon Society, New York, USA.

Foster, J.B. (2003) A planetary defeat: the failure of global environmental reform. Monthly Review, 54, January, 1-9.

Hay, J. (1969) In Defense of Nature. Little, Brown and Company, Boston, USA.

Hay, J. (1987) The Immortal Wilderness. W.W. Norton, New York, USA.

Kahn, P.H., Jr. (1999) The Human Relationship with Nature: Development and Culture. MIT Press, Cambridge, USA.

Kellert, S.R. (1997) Kinship to Mastery: Biophilia in Human Evolution and Development. Island Press, Washington, DC, USA.

Kellert, S.R. (1985) Attitudes toward animals: age-related development among children. Journal of Environmental Education, 16, 29-39.

Kellert, S.R. \& Wilson, E.O. (eds) (1993) The Biophilia Hypothesis. Island Press, Washington, DC, USA.

Lopez, B. (2001) The naturalist. Orion, 20, 4, 38-43.

Leopold, A. (1949) The land ethic. In A Sand County Almanac and Sketches Here and There. Oxford University Press, New York, USA.

Mabey, R. (1973) The Unofficial Countryside. Collins, London, USA.

McNeely, J. (2002) Threatened and threatening: our love-hate relationship with nature and its conservation. In Life Counts: Cataloguing Life on Earth (eds M.D. Gleich, D. Maxeiner, M. Miersch \& F. Niclay), pp. 116-127. Atlantic Monthly Press, New York, USA.

Murphy, D.E. (2002). Power plant approval on land tribes hold sacred. New York Times News Service, 1 December.

Nabhan, G.P. \& Trimble, S. (1994) The Geography of Childhood: Why Children Need Wild Places. Beacon Press, Boston, USA.

New, T., Pyle, R.M., Thomas, J.A., Thomas, C.D. \& Hammond, P.C. (1995) Butterfly conservation management. Annual Review of Entomology, 40, 57-83.

Orr, D.W. (1994) Earth in Mind: On Education, Environment, and the Human Prospect. Island Press, Washington, DC, USA.

Population Connection (2003). Population Connection: Education and Action for a Better World. http:// www.populationconnection.org [accessed 28 March 2003].
Pyle, R.M. (1978) The extinction of experience. Horticulture, 56, 64-67.

Pyle, R.M. (1986) Wintergreen: Rambles in a Ravaged Land. Charles Scribner's Sons, New York, USA (2001 edition, Sasquatch Books, Seattle, USA).

Pyle, R.M. (1993) The Thunder Tree: Lessons from an Urban Wildland. Houghton Mifflin, Boston, USA.

Pyle, R.M. (2000) Resurrection Ecology: bring back the Xerces Blue. Wild Earth, 10, 30-34.

Pyle, R.M. (2001) The rise and fall of natural history: how a science grew that eclipsed direct experience. Orion, 20, 17-23.

Pyle, R.M. (2002) Eden in a vacant lot: kids and species in the neighborhood of life. In Children and Nature: Psychological, Sociological, and Evolutionary Investigations, (eds P.H. Kahn \& S.R. Kellert), pp. 305-327. MIT Press, Cambridge, USA.

Pyle, R.M., Bentzien, M. \& Opler, P.O. (1981) Insect conservation. Annual Review of Entomology, 26, 233-58.

Sanderson, S. (2002) The future of conservation. Foreign Affairs, 81, 162-173.

Scheffer, V. (1991) The Shaping of Environmentalism in America. University of Washington Press, Seattle, USA.

Sobel, D. (1993) Children's Special Places: Exploring the Role of Forts, Dens, and Treehouses in Middle Childhood. Zephyr Press, Tucson, USA.

Speth, J.G. (2002) A new green regime: attacking the root causes of global environmental deterioration. Environment Yale, 1, 20.

Thomashow, M. (2001) A biospheric natural history. Orion, 20, 24-37.

Wilson, E.O. (1984) Biophilia: The Human Bond with Other Species. Harvard University Press, Cambridge, USA.

\section{Biographical sketch}

Robert Michael Pyle received a PhD in ecology and environmental studies from Yale University in 1976, and has been an independent writer and biologist since 1982. Founder of the Xerces Society for invertebrate conservation, he served as chair of the Lepidoptera Specialist Group of IUCN and co-compiler of the Invertebrate Red Data Book. He is former Northwest Land Steward for The Nature Conservancy and consultant to the Wildlife Department of Papua New Guinea, and received a 1997 Distinguished Service Award from the Society for Conservation Biology. Pyle's 14 books have earned numerous awards including the John Burroughs Medal and a Guggenheim Fellowship. 